75 years of Agricultural University - Plovdiv

JUBILEE SCIENTIFIC INTERNATIONAL

CONFERENCE Plovdiv 26-28 November 2020
PERSPECTIVES ON AGRICULTURAL SCIENCE AND INNOVATIONS FOR SUSTAINABLE FOOD SYSTEMS

\title{
DOI: 10.22620 /agrisci.2021.30.009 \\ THE POTENTIAL BENEFIT OF THE USE OF SEASONAL FORECAST DURING THE AGRICULTURAL ECONOMIC YEAR 2019-2020 IN BULGARIA
}

\author{
Ilian Gospodinov*, Valentin Kazandjiev, Veska Georgieva \\ National Institute of Meteorology and Hydrology \\ 1784 Sofia, 66 Tsarigradsko shose \\ *E-mail: Ilian.Gospodinov@meteo.bg
}

\begin{abstract}
Seasonal forecasting gained ground in the last decades by building up knowledge on the processes staying behind the climate variability at the seasonal time scale, constructing ever more sophisticated general circulation models and ensemble prediction systems and thus enhancing forecast skill. The seasonal forecast is a climate forecast and is therefore probabilistic in nature. The predictability of the atmospheric circulation at the seasonal scale is limited in the middle latitudes, where Europe and Bulgaria are situated, by its chaotic nature. The current standard is to give forecast of the potential anomalies of the mean seasonal temperature and the seasonal amount of precipitation. The National Institute of Meteorology and Hydrology of Bulgaria has been issuing operationally seasonal forecast for the country since 2005. The goal of this work is to discuss the seasonal forecast for the last agricultural year 2019-2020. The year was characterized by its drought conditions especially in Eastern Bulgaria. This work would show the extent to which it was successfully predicted and how the seasonal forecast could have been used for decision making. The use of agrometeorological indices for the analysis of the skill of the seasonal forecast has been shown.
\end{abstract}

Key words: seasonal forecast, active temperature sum, precipitation sum, anomaly, vegetation period

\section{INTRODUCTION}

Seasonal forecasting has become more skillful and hence more attractive in the recent years (Stringer et al., 2020; Johnson et al., 2019). However its use is not straightforward and requires certain level of understanding. The seasonal forecast is often misinterpreted and one can easily decide that it is not useful or it can be overconfident (Troccoli, 2010).

The weather and climate prediction has limitations defined by the dynamics of the atmosphere and the natural lifetime of the different atmospheric processes that we call "weather". For example an atmospheric front evolves within the time frame of days and it is therefore predictable in the same time scale. A thunderstorm lives for hours and is therefore predictable only hours ahead. The climate variability at the seasonal time scale is predictable to some extend thanks to the predictability of the state of the earth's surface in terms of the anomalies in the sea-surface temperature and the soil-moisture content. The patterns of the sea-surface temperature anomalies indeed evolve in the time frame of seasons (Sutton \& Hudson, 2005). The soil moisture content anomalies are more variable and can persist for months (Whana et al., 2015). The interaction of the atmosphere with the anomalous surface state increases the chance for a departure of the atmospheric circulation from its long term average and this is the simplest rapid explanation of what makes the seasonal forecasting possible. The slow evolution of the state of the earth's surface allows the prediction 
75 years of Agricultural University - Plovdiv JUBILEE SCIENTIFIC INTERNATIONAL CONFERENCE Plovdiv 26-28 November 2020
PERSPECTIVES ON AGRICULTURAL SCIENCE AND INNOVATIONS FOR SUSTAINABLE FOOD SYSTEMS of potential anomalies of the climate of an upcoming season.

Unfortunately the predictability of the climate variations at the seasonal scale in the middle latitudes is limited by natural factors. The atmospheric circulation is dominated by the west-east flow whose fluctuations are often self dependent and their long term behavior is chaotic and unpredictable. The big predictable climate scale structures are found in the tropics and the best known of them is El Nino Southern Oscillation (Hu et al., 2019). El Nino or La Nina episodes in the tropical Pacific can influence the weather in the middle latitudes, especially in the neighboring continents. Europe, however, is far from the Pacific and the influence of El Nino is indirect and as a consequence - small. These factors make so that the seasonal forecast in Europe has low skill.

The goal of a seasonal forecast is to say what the potential anomalies of the meteorological parameters would be at the time scale of a whole season. The most popular parameters are temperature and precipitation and therefore it is common to give seasonal forecast of the mean seasonal temperature and the seasonal amount of precipitation. The seasonal forecast is probabilistic. The standard distribution of the departure of the meteo parameters from normal in long-term time series defines the indifferent climate forecast. On that basis, it can be said that the mean seasonal temperature or the seasonal amount of precipitation can be below, near, or above normal with equal probability of $33.3 \%$. The threshold values separating the below, near, and above normal intervals are defined for each individual station based on its long-term data record. The seasonal forecast says how the probability to fall in each of the three intervals changes with respect to the current state of the earth's climate system.

Many seasonal scale structures have been identified and studied. They are referred to as predictors. For some of them simple statistics-based predictions can be made. However, most of the time, different predictors play in opposite directions. This is where the role of the global general circulation atmospheric numerical models comes. There are a number of global prediction centers designated by the World meteorological organization (Graham et al., 2011). They provide operational production of seasonal forecasts for up to 8 months based on ensemble prediction systems. Practically all of them are freely available online. They give maps of forecast probabilities for hitting one of the three categories below/near/above normal. They lay behind most of the seasonal predictions dedicated to the general public. However caution is needed when interpreting those materials. The difficulty comes from the expectation of the public to be given deterministic forecast and a rapid loss of interest to probabilistic seasonal forecast.

The rest of the paper illustrates the current practice of seasonal forecast for the general public in the National Institute of Meteorology and Hydrology (NIMH) of Bulgaria which is the national weather service. It reviews in a greater detail the seasonal forecast for the agricultural year of 2019-2020 which was marked by drought conditions. The paper elucidates the success value of the seasonal forecast. Some interpretation of how it would have helped the agribusiness has been given at the end.

\section{DATA AND METODS}

NIMH issues a monthly hydrometeorological bulletin (see references) where an analysis of the monthly mean temperature and the monthly amount of precipitation from climate perspective can be found. The seasonal maps of temperature and precipitation for the last calendar season can be found on the website of NIMH (www.meteo.bg). These products are based on data from the operational meteorological stations of NIMH. They include 
75 years of Agricultural University - Plovdiv JUBILEE SCIENTIFIC INTERNATIONAL CONFERENCE Plovdiv 26-28 November 2020
PERSPECTIVES ON AGRICULTURAL SCIENCE AND INNOVATIONS FOR SUSTAINABLE FOOD SYSTEMS more than 40 synoptic stations and additional climate stations that constitute a network of more than 100 stations. All maps given in this paper are operational products of NIMH based on operational weather data. NIMH monitors about 30 stations for the operational seasonal forecasting. The indices used for seasonal forecasting are based on data from those 30 stations. The principles of quantifying the seasonal forecast are described in each seasonal forecast document issued by NIMH on their website.

\section{THE AGRICULTURAL YEAR 2019-2020 FROM CLIMATE PERSPECTIVE}

Fig. 1. shows the spatial distribution of the departure from the climate normal of the mean seasonal temperature for all four calendar seasons from autumn 2019 to summer 2020. Fig. 2. shows the spatial distribution of the seasonal rainfall in percent of the climate normal for all four calendar seasons from autumn 2019 to summer 2020. The baseline time frame is still the WMO's last recommended 30-year period 1961-1990. The intraseasonal variability of precipitation can be seen in Fig. 3. It shows the spatial distribution of the monthly precipitation amount in percent of the climate normal. The seasons and months on the figures cover the so-called agricultural year 2019-2020. The months are from June 2019 to September 2020. This includes the summer months of 2019 in order to illustrate the end of a wet period in the summer of 2019 and the beginning of the dry conditions in autumn 2019.

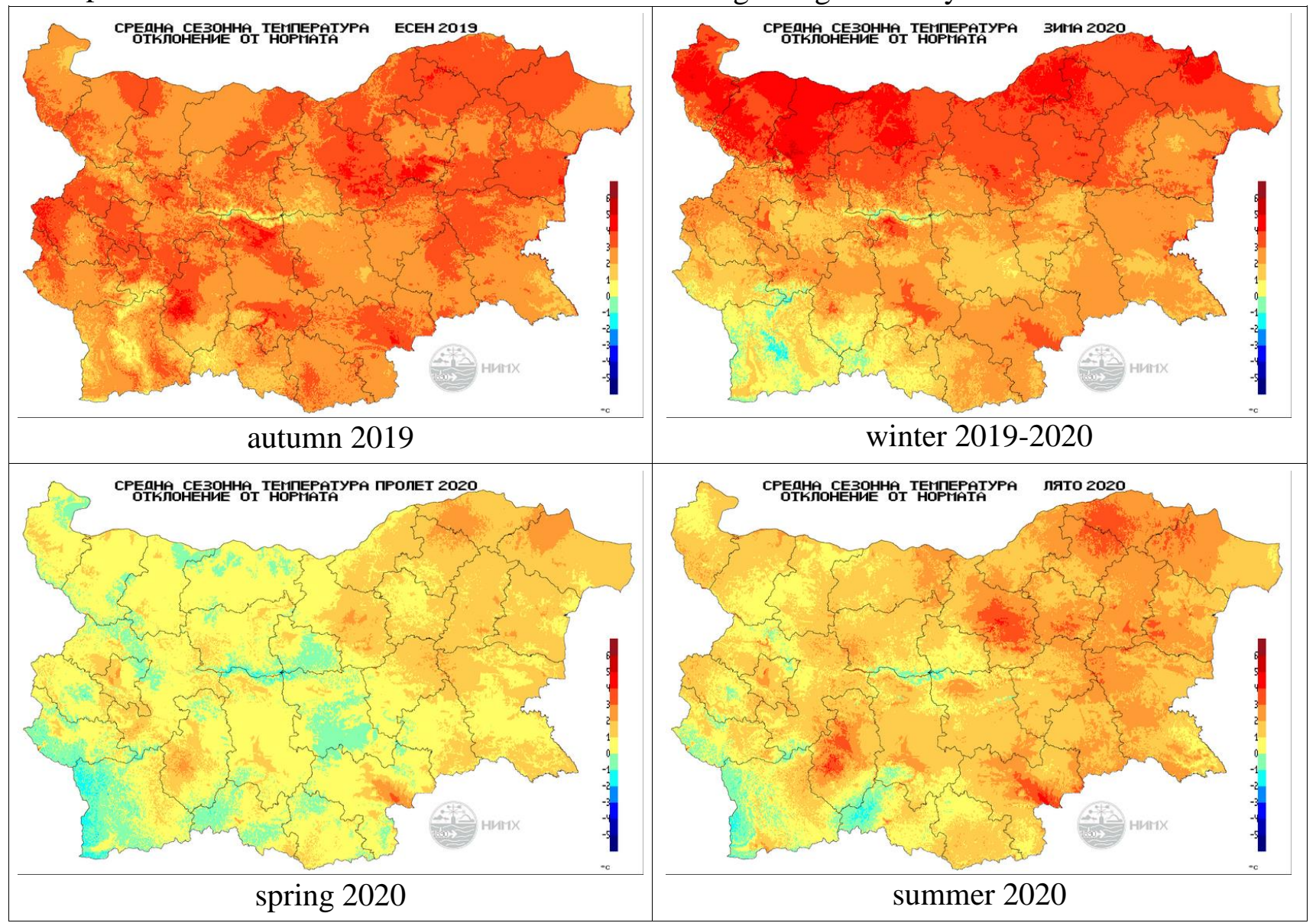

Fig. 1. Spatial distribution of the departure of the seasonal mean temperature from the climate seasonal norm (baseline period 1961-1990). Autumn 2019 - summer 2020. 
75 years of Agricultural University - Plovdiv JUBILEE SCIENTIFIC INTERNATIONAL CONFERENCE Plovdiv 26-28 November 2020
PERSPECTIVES ON AGRICULTURAL SCIENCE AND INNOVATIONS FOR SUSTAINABLE FOOD SYSTEMS

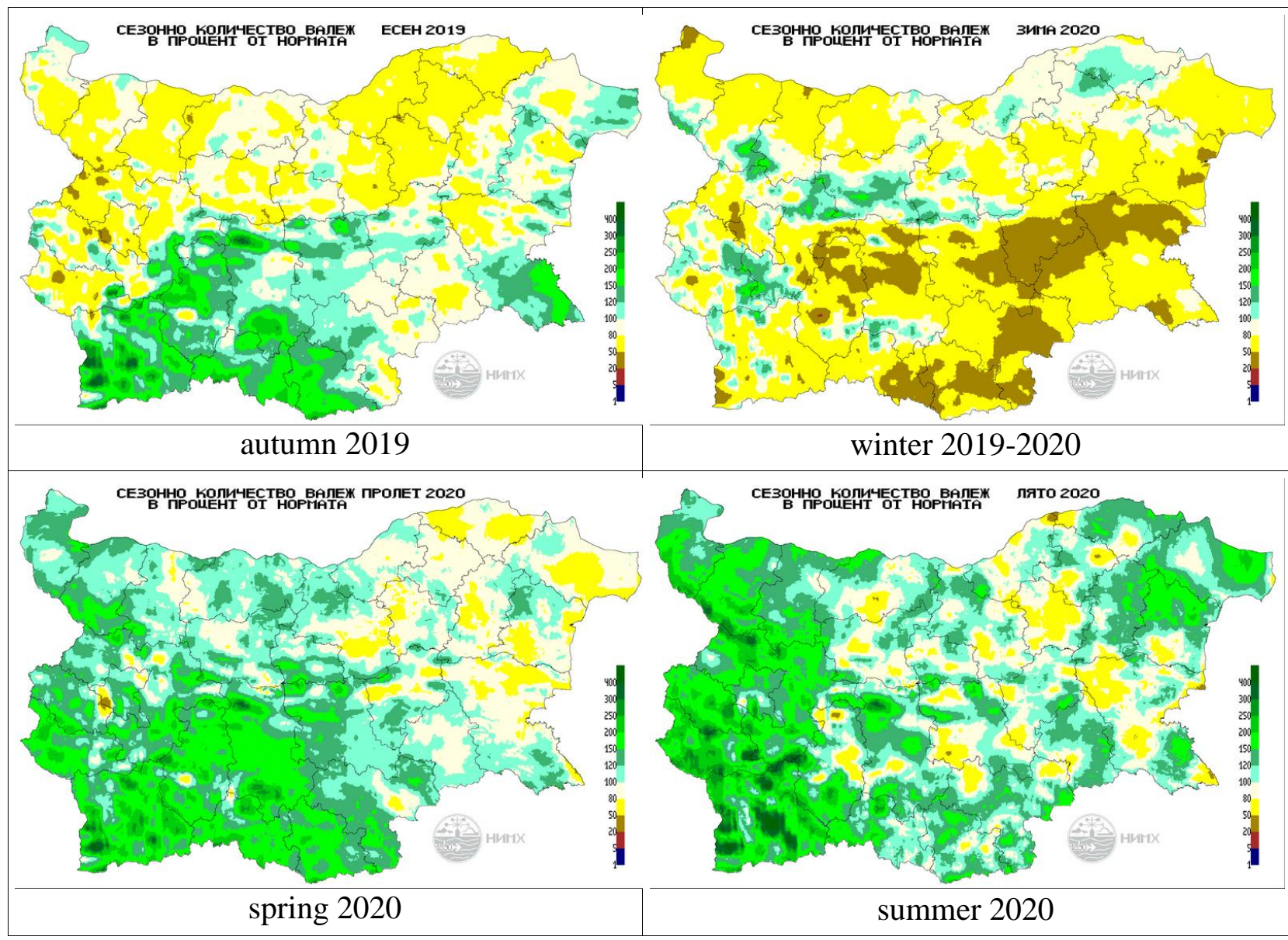

Fig. 2. Spatial distribution of the departure of the seasonal amount of precipitation in percent of the normal (baseline period 1961-1990). Autumn 2019 - summer 2020.

It can be seen for temperature (Fig. 1.) that the autumn 2019 and winter 2019-2020 were very warm with $3-4^{\circ} \mathrm{C}$ above normal and especially in the Northeast Bulgaria. The spring and summer of 2020 were with temperature rather near or above normal for the country as a whole but for the Northeast Bulgaria they were $1-2^{\circ} \mathrm{C}$ above normal. The analysis of the intraseasonal variability reveals a very warm November 2019 with monthly temperatures 5$6^{\circ} \mathrm{C}$ above normal in the Northeast Bulgaria and a very warm February 2020 with mean monthly temperatures $4-5^{\circ} \mathrm{C}$ above normal in the Northeast Bulgaria (not illustrated). The spring months of April and May and the month of June were with temperatures near normal or even slightly below normal in April but in the northeast they were around $1{ }^{\circ} \mathrm{C}$ above normal. The rest of the summer of 2020 and September 2020 were moderately warm. In summery the agricultural year was relatively warm except for the 3-month period April-June 2020 where it was rather near normal. However the northeast was warm all year round.

In terms of precipitation in the Northeast Bulgaria the seasons were with seasonal amounts of precipitation within 50 to $120 \%$ of the climate normal for autumn 2019, winter 2019-2020, and spring 2020 (Fig. 2). The summer of 2020 in the Northeast Bulgaria was with seasonal rainfall between 80 and $200 \%$ of the normal. In average for the country the seasons of autumn 2019 was around normal in terms of precipitation, the winter was either 
75 years of Agricultural University - Plovdiv JUBILEE SCIENTIFIC INTERNATIONAL CONFERENCE Plovdiv 26-28 November 2020
PERSPECTIVES ON AGRICULTURAL SCIENCE AND INNOVATIONS FOR SUSTAINABLE FOOD SYSTEMS normal or dry, the spring and summer 2020 were either normal or wet. The drought therefore is not easily seen in the seasonal time scale of precipitation anomalies. The intraseasonal variation (Fig. 3.) however reveals monthly anomalies to the dry side in the Northeast Bulgaria in August and September 2019 and in January and April 2020, and July and August 2020.

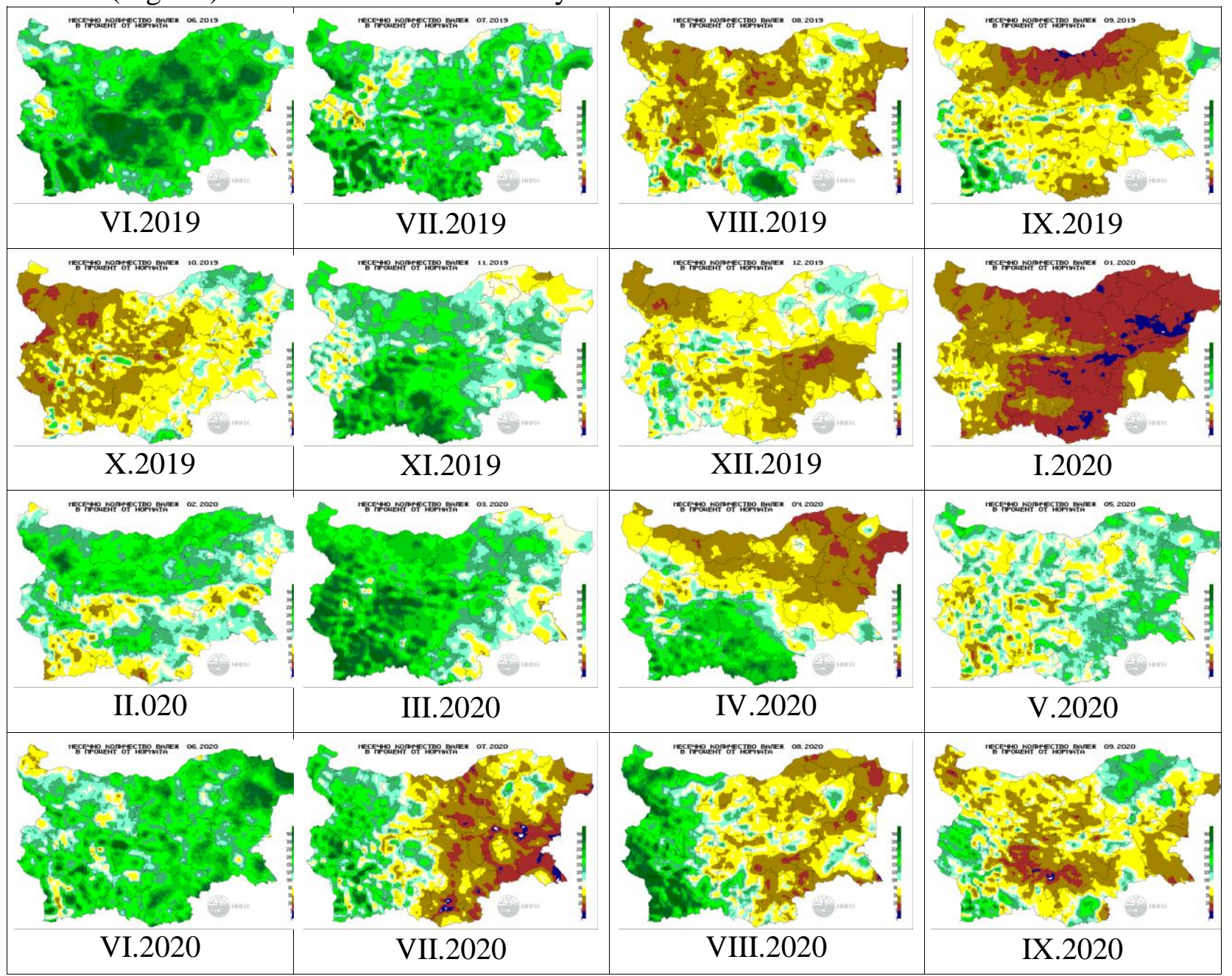

Fig. 3. Spatial distribution of the monthly precipitation amount in percent of the climate normal for the period 1961-1990. June 2019 - September 2020.

The month of January was very dry with less than $20 \%$ of the normal for the whole northeast. In summery the agricultural year was with precipitation around the normal except for the winter 2019-2020 where the southeast was rather dry. The northeast however was with precipitation near or slightly below normal through the seasons except for the summer where it was near or above normal. The intraseasonal variation, however, shows months with very dry conditions.

\section{THE SEASONAL FORECAST FOR TEMPERATURE AND PRECIPITATION FOR THE SEASONS OF THE AGRICULTURAL YEAR 2019-2020}

The official seasonal forecast of NIMH is designed to give overall prediction of the potential anomalies of the mean seasonal 
75 years of Agricultural University - Plovdiv JUBILEE SCIENTIFIC INTERNATIONAL CONFERENCE Plovdiv 26-28 November 2020
PERSPECTIVES ON AGRICULTURAL SCIENCE AND INNOVATIONS FOR SUSTAINABLE FOOD SYSTEMS temperature and seasonal rainfall for the current and the next coming seasons. The forecast for the current season is updated as it goes. The update takes in consideration the evolution of the $1^{\text {st }}$ or the $2^{\text {nd }}$ month of the current season that have already elapsed. The first forecast for an upcoming season takes place about 2 months before its beginning and it is updated twice. The last real forecast take place a few days before the beginning of the season. The intraseasonal variation is given as well. The potential anomalies of the individual months are given up to the third upcoming month. One of its aspects among the science based 3-months outlook is that it has been designed to fit the overall forecast anomaly. For example the probability for cold individual months can not be high if the overall forecast for the season is to be warm. The forecast is given in color tables. The legend is given together with the table. The forecast says what the most likely category is (selected one) or the two neighbors most likely categories are (excluded one). There is a score system based on a climate index of temperature and precipitation. The index has been designed to measure whether the season was very warm/wet everywhere in the country $(+2)$ or very cold/dry everywhere (-2). In it is around normal the index is around 0 . If in part of the country was cold/dry or warm/wet and in others normal the index is around minus or plus 1 . There is a single index for the country as a whole and the seasonal forecast is given as a prediction for the value of the index. The departure of the forecast index from the measured one is a measure of the success of a given individual forecast. It is a deterministic approach to the evaluation of the probabilistic forecast. This approach facilitates the communication of the forecast skill to the general public. If the departure is within \pm 0.5 the forecast is excellent and scores 4 . If it is within \pm 0.5 to \pm 1.0 it is very good and scores 3 . If it is within \pm 1.0 to \pm 1.5 the forecast is good and scores 2 because it is not misleading. It the departure is beyond \pm 1.5 the forecast is misleading and scores 0 . If there is not an issued specific forecast the climate probabilities of $33.3 \%$ apply and the forecast scores 1 (a reasonable forecast because not misleading).

Table 1 shows the forecast and the resulting anomaly for months and seasons of the agricultural year 2019-2020. Table 3 shows the seasonal outlook by months and the observed anomaly index for the individual months for all seasons from summer 2019 to summer 2020. Scores of the forecast appear in column "Scores".

Table 1. Seasonal forecasts issued for the seasons from summer 2019 to summer 2020 together with observed anomaly index and

\begin{tabular}{|c|c|c|c|c|c|c|c|c|}
\hline & \multicolumn{4}{|c|}{ scores. } & & & & \\
\hline & & \multicolumn{3}{|c|}{$\begin{array}{l}\text { Forecast } \\
\text { issued 1, } 2, \\
\text { or } 3 \\
\text { months in } \\
\text { advance }\end{array}$} & \multirow[b]{2}{*}{ Index } & \multicolumn{3}{|c|}{ Score } \\
\hline & Season & -1 & -2 & -3 & & -1 & -2 & -3 \\
\hline \multirow{5}{*}{$\begin{array}{l}\text { Tempe- } \\
\text { rature }\end{array}$} & Summer 2019 & 1 & 1 & 1 & 1,73 & 3 & 3 & 3 \\
\hline & Autumn 2019 & 1 & 1 & 1 & 2,00 & 3 & 3 & 3 \\
\hline & Winter 2019-2020 & 1 & 1 & 1 & 1,98 & 4 & 3 & 3 \\
\hline & Spring 2020 & 2 & 2 & 1 & 0.96 & 2 & 2 & 4 \\
\hline & Summer 2020 & 1 & 1 & 1 & 1.24 & 4 & 4 & 4 \\
\hline \multirow{5}{*}{$\begin{array}{l}\text { Precipi- } \\
\text { tation }\end{array}$} & Summer 2019 & & 1 & 0 & 0,47 & 1 & 3 & 4 \\
\hline & Autumn 2019 & 0 & 1 & 0 & $-0,84$ & 3 & 0 & 3 \\
\hline & Winter 2019 & -1 & -1 & -1 & $-1,06$ & 4 & 4 & 4 \\
\hline & Spring 2020 & & -1 & & 0.42 & 1 & 2 & 1 \\
\hline & Summer 2020 & -1 & -1 & -1 & -0.05 & 3 & 3 & 3 \\
\hline
\end{tabular}

The seasonal forecast for temperature looks very successful with average score 3.2 (very good) and individual forecasts scoring not less than 2 (good). However one should be aware that the temperature forecast is very much dominated by the global warming trend. Practically, there were no really cold seasons in the last years. The last cold season was the winter of 2016-2017 where the month of January 2017 was very cold. The high score for temperature therefore is not very interesting. The really interesting forecast is for precipitation and that is what would have made a great impact. The seasonal forecast for precipitation scores 2.6 which is very good but 
75 years of Agricultural University - Plovdiv JUBILEE SCIENTIFIC INTERNATIONAL CONFERENCE Plovdiv 26-28 November 2020
PERSPECTIVES ON AGRICULTURAL SCIENCE AND INNOVATIONS FOR SUSTAINABLE FOOD SYSTEMS at the lower end of the interval for very good. There are 3 times with no specific forecast issued. And one bad hit (score 0 - misleading). The winter forecast however was very successful scoring 4.0 (excellent) followed by the summer 2020 forecast scoring 3.0 (very good). These seasons were either dry (winter 2020) or rather to the dry side (summer 2020).

The average scores for the seasonal outlook by months for temperature and precipitation are 2.8 (very good) and 2.3 (good) respectively. They are lower if compared to the scores of the seasonal outlooks for the same seasons as a whole. The temperature forecast is again more successful than the precipitation forecast, but it is not of great interest because there were no cold months. The coldest three months were April, May and June 2020 and they fell within the normal range on average for the country.

Table 2. Probabilistic qualitative categories used for the seasonal forecast.

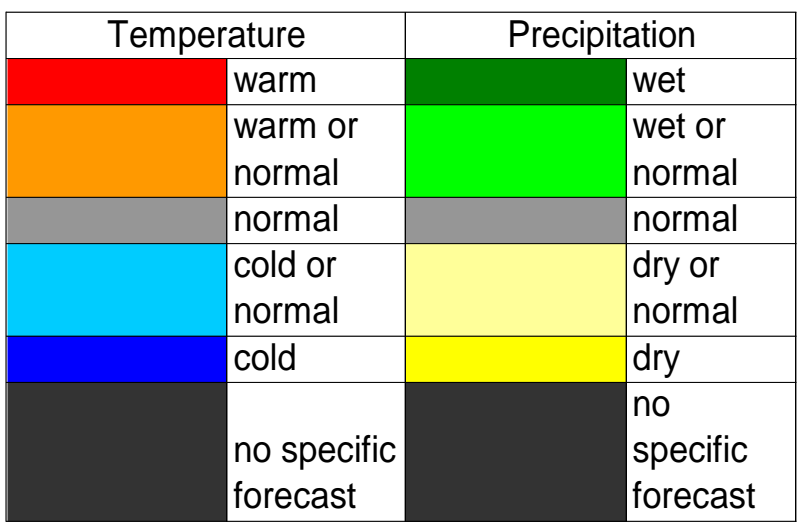

The precipitation forecast is good in general. This means that the very good forecasts outnumber the misleading ones. The best forecasts are for the months of September 2020, July 2020, December 2019, and January 2020. All these months were rather dry. The worst forecasts are for the months of February 2020, June 2020, and November 2019 each of them with 2 misleading forecasts. Those least successful forecasts were for rather dry months and they were following the overall seasonal forecast for dry. However the months turned to be rather wet. By occasion this illustrates the limitations of the forecast for the intraseasonal variations

Table 3. Seasonal outlook by months issued for the months from June 2019 to September 2020 together with observed anomaly index and scores.

\begin{tabular}{|c|c|c|c|c|c|c|c|c|}
\hline & & \multirow{2}{*}{\multicolumn{3}{|c|}{\begin{tabular}{|l|} 
Forecast \\
issued 1, 2, \\
or 3 \\
months in \\
advance
\end{tabular}}} & & & & \\
\hline & & & & & & \multicolumn{3}{|c|}{ Score } \\
\hline & Month & -1 & -2 & -3 & Index & -1 & -2 & -3 \\
\hline \multirow{16}{*}{$\begin{array}{l}\text { Tempe- } \\
\text { rature }\end{array}$} & June 2019 & 1 & 0 & 1 & 1,84 & 3 & 0 & 3 \\
\hline & July 2019 & 1 & 1 & 1 & 0,38 & 3 & 3 & 3 \\
\hline & August 2019 & 0 & 1 & 1 & 1,71 & 0 & 3 & 3 \\
\hline & September 2019 & 1 & 1 & 1 & 2,00 & 3 & 3 & 3 \\
\hline & October 2019 & 1 & 1 & 1 & 1,84 & 3 & 3 & 3 \\
\hline & November 2019 & 1 & 1 & 0 & 2,00 & 3 & 3 & 0 \\
\hline & December 2019 & 1 & 1 & 1 & 1,84 & 3 & 3 & 3 \\
\hline & January 2020 & 1 & 1 & 1 & 1,51 & 3 & 4 & 3 \\
\hline & February 2020 & 1 & 1 & 1 & 2,00 & 3 & 3 & 3 \\
\hline & March 2020 & 2 & 1 & 1 & 1.51 & 4 & 3 & 3 \\
\hline & April 2020 & 0 & 1 & 1 & 0.02 & 4 & 3 & 3 \\
\hline & May 2020 & 1 & 1 & 1 & -0.09 & 2 & 2 & 2 \\
\hline & June 2020 & 0 & 1 & 1 & -0.16 & 4 & 2 & 2 \\
\hline & July 2020 & 0 & 1 & 1 & 1.27 & 2 & 4 & 4 \\
\hline & August 2020 & 1 & 1 & 1 & 1.51 & 3 & 3 & 3 \\
\hline & September 2020 & 1 & 1 & 2 & 2.00 & 3 & 3 & 4 \\
\hline \multirow{16}{*}{$\begin{array}{l}\text { Precipi- } \\
\text { tation }\end{array}$} & June 2019 & 1 & 1 & 0 & 1,21 & 4 & 4 & 2 \\
\hline & July 2019 & 0 & & 0 & 0,69 & 3 & 1 & 3 \\
\hline & August 2019 & 0 & 0 & & $-1,06$ & 2 & 2 & 1 \\
\hline & September 2019 & & 0 & 0 & $-0,99$ & 1 & 3 & 3 \\
\hline & October 2019 & 0 & 0 & 1 & $-0,79$ & 3 & 3 & 0 \\
\hline & November 2019 & -1 & -1 & 1 & 0,64 & 0 & 0 & 4 \\
\hline & December 2019 & 0 & -1 & -1 & $-1,26$ & 2 & 4 & 4 \\
\hline & January 2020 & -1 & -1 & -1 & $-1,68$ & 3 & 3 & 3 \\
\hline & February 2020 & -1 & -1 & 0 & 1,04 & 0 & 0 & 2 \\
\hline & March 2020 & 0 & -1 & & 1.21 & 2 & 0 & 1 \\
\hline & April 2020 & 0 & & & -0.72 & 3 & 1 & 1 \\
\hline & May 2020 & -1 & -1 & & -0.02 & 3 & 3 & 1 \\
\hline & June 2020 & 0 & -1 & -1 & 0.69 & 3 & 0 & 0 \\
\hline & July 2020 & 0 & -1 & -1 & -0.94 & 3 & 4 & 4 \\
\hline & August 2020 & -1 & & -1 & -0.44 & 3 & 1 & 3 \\
\hline & September 2020 & -1 & -1 & -1 & -0.67 & 4 & 4 & 4 \\
\hline
\end{tabular}

\section{DISCUSSIONS}

The really important question is what would have helped to prepare for the drought in the Northeast Bulgaria in the last agricultural 
75 years of Agricultural University - Plovdiv

JUBILEE SCIENTIFIC INTERNATIONAL

CONFERENCE Plovdiv 26-28 November 2020
PERSPECTIVES ON AGRICULTURAL SCIENCE AND INNOVATIONS FOR SUSTAINABLE FOOD SYSTEMS year. Would the seasonal forecast have been helpful?

The seasonal forecast for temperature would have been helpful beyond doubt but this would have not helped much for predicting the drought. The seasonal forecast for precipitation would not have been very helpful to prepare for dry autumn because the forecast was for either normal or wet while the autumn turned to be to the dry side. The same applies for the spring forecast. There was either no specific forecast issued or the forecast was for a dry spring while it turned out to be normal on average but rather to the wet side. The winter forecast however was successful. It was for a dry winter and it turned out to be mostly dry. The summer 2020 forecast was very good. It was for a dry summer and the season turned out to be within the normal range but rather to the dry side.

Agribusiness is a paramount user of the seasonal forecasts. It would provide the decision makers with a valuable tool for planning specific tasks. The seasonal forecasts create conditions for preparedness connected with a crop selection in order to make an optimal use of agro-meteorological conditions to avoid the risky periods under which crops cannot realize their potential productivity. The seasonal forecast for dry and warm winter was first issued in September 2019. At that moment the already rigid summer drought was being transformed into autumn one. Farmers would have made an informed choice about the wheat crops by having in hand the forecast of an increased chance for a warm and dry winter.

What should be considered when choosing a variety of wheat, depending on the climatic conditions? Recent climate studies suggest that the winters in the last 30 years tend to be less cold and the snow depth tends to be lower than before. The permanent transitions through $5^{\circ} \mathrm{C}$ and the attenuation of the vegetation take place later and later with a sharp decrease in temperatures, which complicates the hardening processes, and the dormancy period becomes shorter and shorter with longer and longer winter warming. Under these conditions, the plants had periods of vegetation and during the winter drought began to turn yellow due to the lack of effective supply of nutrients. It is exactly in years with extreme weather where the domestic varieties of crops showed their advantages and could become a natural choice for farmers if provided with a more accurate seasonal forecast. It is known that the domestic varieties of crops are better adapted to the local high amplitude climate variations than the introduced varieties.

The seasonal forecasts could help farmers decide whether to shift the terms of sowing in order to avoid unfavorable hydrothermal conditions, pest invasions, seasonal diseases and weeds. The seasonal forecasts could help plan the application of modern techniques like pre-sowing irrigation. There are recent studies showing that pre-sowing watering of $40 \mathrm{~m}^{3} / \mathrm{dka}$ improves the rate of germination and the following growth and stabilizes the final yields (Zhivkov, 2013). The autumn water consumption is $10-15 \%$ from the total, for the whole vegetation period. The seasonal forecasts could also facilitate the planning of fertilization and the choice of fertilizers and their combinations.

The planning of the sowing for the spring crops is another potential beneficial use of the good seasonal forecasts. A warm spring would allow farmers to plan for an early sowing and thus avoid the summer drought. Orchards and vineyards however would be forced to have a premature awakening and that would increase the risk of frost damages. A good forecast would help farmers act preventively.

\section{CONCLUSIONS}

The seasonal forecast in general for the region of Europe including Bulgaria has limitations that relate to the chaotic nature of the atmospheric circulation in the middle latitudes. 
75 years of Agricultural University - Plovdiv JUBILEE SCIENTIFIC INTERNATIONAL CONFERENCE Plovdiv 26-28 November 2020
PERSPECTIVES ON AGRICULTURAL SCIENCE AND INNOVATIONS FOR SUSTAINABLE FOOD SYSTEMS
The seasonal forecast for precipitation is even less skillful due to intrinsic properties of rain processes. However, some trends towards either dry of wet can be predicted successfully as was the case for the winter of 2019-2020. Businesses that would have followed the forecast and prepared for a dry winter would have made economic gains. The use of probabilistic seasonal forecast is more complicated than that and requires a long term commitment. Nevertheless this work illustrated that quite very often, like in the last winter, the forecast was useful and would have made a significant positive economic impact if applied.

Seasonal forecasting for agricultural applications should strengthen its capacity to predict occurrence of critically low temperatures in winter and critically high temperatures in summer. Another potentially beneficial seasonal forecast skill would be to allow for a higher resolution.

\section{ACKNOWLEDGMENT}

This work was supported by the Bulgarian Ministry of Education and Science under the National Research Programme "Healthy Foods for a Strong Bio-Economy and Quality of Life" approved by DCM \# 577 / 17.08.2018.

\section{REFERENCES}

Graham, R. J., Yun, W.-T., Kim, J., Kumar, A., Jones, D., Bettio, L., Gagnon, N., Kolli, R. K., Smith, D., 2011: Long-range forecasting and the Global Framework for Climate Services. Climate Research, 47, 47-55

Hu, Z., A. Kumar, J. Zhu, P. Peng, and B. Huang, 2019: On the Challenge for ENSO Cycle Prediction: An Example from NCEP Climate Forecast System, Version 2. J. Climate, 32, 183-194

Johnson, S. J., Stockdale, T. N., Ferranti, L.,
Balmaseda, M. A., Molteni, F., Magnusson, L., Tietsche, S., Decremer, D., Weisheimer, A., Balsamo, G., Keeley, S. P. E., Mogensen, K., Zuo, H., \& Monge-Sanz, B. M. (2019). SEAS5: the new ECMWF seasonal forecast system. Geoscientific Model Development, 12(3), 1087-1117

Monthly Hidro-meteorological Bulletin of NIMH, ISSN 1314-894X, www.meteo.bg

Murphy, A. H., S. Lichtenstein, B. Fischhoff, and R. L. Winkler, 1980: Misinterpretations of Precipitation Probability Forecasts. Bull. Amer. Meteor. Soc., 61, 695-701

Stringer, N., J. Knight, and H. Thornton, 2020: Improving Meteorological Seasonal Forecasts for Hydrological Modeling in European Winter. J. Appl. Meteor. Climatol., 59, 317-332

Sutton, R. T. and D. L. R. Hodson, 2005: Atlantic Ocean Forcing of North American and European

Summer Climate. Science 01, Vol. 309, Issue 5731, pp. 115-118

Troccoli, A., 2010: Review Seasonal Climate Forecasting. Meteorol. Appl., 17, 251268

Whana, K., Zscheischlerb, J., Orthc, O., Shongwed, M., Rahimie,M., Asaref, E. O., Seneviratne, S. I., 2015: Impact of soil moisture on extreme maximum temperatures in Europe. Weather and Climate Extremes, 9, 57-67

Zhivkov, Zh. (2013). Napoyavane na zemedelskite kulturi [The irrigation of the agricultural crops]. $211 \mathrm{p}$. 